\section{SKIN DISEASES IN GENERAL PRACTICE.}

\author{
(Third Edition).
}

By H. Haldin-Davis, D.M., M.A. Oxon., F.R.C.P. Oxford University Press. 1937. $17 / 6$.

There are now many books on Dermatology by British authors suitable for students and general practitioners. The difficulty will be for them to choose. One crucial point which will help their decision is the number and quality of the photographs, as these are the best aids, apart from clinical material, to give students a reliable mental picture of eruptions. Correct diagnosis is the essential precursor to successful treatment. This in many ways excellent edition of Dr. Haldin-Davis' book leaves much to be desired in this respect. There are not nearly sufficient illustrations; e.g. there are no photographs to illustrate the eruption in Pediculosis, Scabies, Rosacea, three very common and important diseases. Some of the illustrations are very poor and really of no value; e.g. on page 137 there is a photograph of Lichen Planus said to "show typical angular papules ". This is a great stretch of the imagination. The coloured plate on page 358 is very good, but a little out of position. The two representing Acne Vulgaris are likewise very poor.

For the classification of skin diseases, which is, in the present state of our knowledge, a difficulty, the author adopts a unique method, viz. the various diseases are grouped according to their typographical distribution, a method which he thinks serves best for the purpose of students. There is certainly something to be said for this method, but we feel that the disadvantages outweigh the advantages e.g. Chapter XI is entitled " Diseases limited in extent but irregular in distribution". Here are collected a great variety of diseases quite unconnected with each other, either ætiologically or clinically, e.g. Lupus, Herpes Zoster, X-ray Dermatitis, Ringworm of the glabrous skin, Nævi, Rodent Ulcers, etc. The reviewer would also like to suggest that the constitutional background, particularly the neurogenic background, in skin disease does not receive the emphasis which it deserves.
However, in spite of the above criticism, the reviewer has no hesitation in saying that the student will find Dr. Halden-Davis' book eminently useful, the subject matter being comprehensive and its presentation attractive. $\mathrm{He}$ will also find all that is necessary in the way of remedies and prescriptions. Indeed, the mere fact that the work has reached a third edition is ample evidence of its merits and that it meets a definite demand.

\section{THE OPERATIONS OF SURGERY.}

By R. P. Rowlands and Philip Turner. Eighth Edition. Vol. 2. London: J. \& A. Churchill, Ltd. Price 36/-.

The second volume of the eighth edition of this standard text-book on operative surgery has been completely revised and much of the subject matter has been rewritten. We can state that the high reputation of this book is further enhanced by the appearance of this latest volume. The authors were fortunate in securing the help of Mr. W. H. Ogilvie, Mr. A. Ralph Thompson, Mr. G. F. Gibberd and Mr. R. C. Brock who have contributed certain excellent chapters.

A detailed account is given of all the operations of surgery together with useful references to the literature. New methods are considered and criticised. In these respects the book is an admirable guide for the candidate preparing for the higher qualifications in surgery. Special attention has been given to the important subject of indications and contra-indications for operations together with an account of the difficulties which may be experienced and the errors which may be committed. This feature is of great value to the practising surgeon. An outstanding feature of this edition is a new chapter on "Some Recent Developments." Amongst other important developments in surgery attention is given to the work of Grey Turner on the Radical Treatment of Carcinoma of the CEsophagus. This chapter contains a considerable amount of stimulating ideas and it will doubtless be still further extended in future editions.

The work is well produced, the type and illustrations are excellent and it is recommended to all who desire to keep abreast with the progress of modern surgery. 